\title{
SPECIAL FEATURES OF THE STRUCTURE AND PHASE COMPOSITION OF A Ti - 23Al - 26Nb/AI LAYERED MATERIAL OBTAINED BY PLASMA-SPARK SINTERING
}

\author{
A. S. Yurovskikh, ${ }^{1}$ S. L. Demakov, ${ }^{1}$ and E. V. Kolosova ${ }^{1}$
}

Translated from Metallovedenie i Termicheskaya Obrabotka Metallov, No. 9, pp. 35 - 40, September, 2012.

\begin{abstract}
Special features of formation of the structure of a layered intermetallic material based on titanium aluminide obtained by the method of plasma-spark sintering of foils are studied. The dependence of the structure on the temperature-and-time treatment parameters is determined.
\end{abstract}

Key words: plasma-spark sintering, intermetallics, titanium aluminides, foils, diffusion, phase diagrams.

\section{INTRODUCTION}

Titanium aluminides and alloys based on them belong to a new class of refractory materials designed for operation at $600-1100^{\circ} \mathrm{C}$. In contrast to traditional structural materials these alloys have a unique set of mechanical properties such as high strength and modulus of elasticity preserved to a high temperature, refractoriness, creep resistance and resistance to oxidation and burning $[1,2]$. Combination of these properties with low density makes them promising materials for the production of refractory and heat-resistant parts for the automotive, gas and aerospace industries. Other advantages of titanium aluminides are low noise characteristics and high antifriction properties. There are experimental data showing that the reactions of chemical interaction between titanium and aluminum can be a base for new processes of fabrication of multilayer and composite materials based on titanium aluminides [3].

However, industrial-scale application of such alloys requires solution of a whole number of materials science problems involving stability of the forming structures and the kinetics of the structural transformations. Commercial use of titanium aluminides is hindered by their inappropriate ductility and fracture toughness and poor processibility at room temperature. This makes the search for new materials based on light intermetallics with high operating properties and the development of methods for their production important tasks [4]. A possible way to raise the ductility of such materials is

1 Ural Federal University in the Name of the First President of Russia B. N. Eltsyn, Ekaterinburg, Russia (e-mail: artem.yurovskikh@gmail.com). alloying with niobium. An urgent enough topic is study of the physical and mechanical properties of intermetallic alloys of the $\mathrm{Ti}-\mathrm{Al}-\mathrm{Nb}$ system [5 - 7]. The $\mathrm{Ti}-\mathrm{Al}-\mathrm{Nb}$ ternary system offers many variants of intermetallic compounds [8] and can be used for creating alloys with various mechanical properties. Control of the microstructure is a key element for obtaining the desired characteristics.

The aim of the present work was to study the special features of the structure and phase composition of a material of the $\mathrm{Ti}-\mathrm{Al}-\mathrm{Nb}$ system produced by the method of plasma spark sintering and their variation in the process of heat treatment. $^{2}$

\section{METHODS OF STUDY}

We studied an intermetallic composite obtained by plasma-spark sintering (PSS) of a pack of alternating foils with a thickness of $80 \mu \mathrm{m}$ from alloy $\mathrm{Ti}-23$ at.\% $\mathrm{Al}-$ 26 at. $\% \mathrm{Nb}$ and commercial aluminum foils with a thickness of $16 \mu \mathrm{m}$. Ti $-23 \% \mathrm{Al}-26 \% \mathrm{Nb}$ is an intermetallic titanium $(\mathrm{O}+\beta)$ alloy with the temperature of the polymorphic transformations $T_{\mathrm{pt}}=995^{\circ} \mathrm{C}$. A study by the method of SEM showed that the initial structure of the alloy was represented by primary segregations of a globular orthorhombic $\alpha_{2}$ phase in a matrix $\beta$-solid solution of Ti (Fig. 1). The surface layers of the foils contained traces of oxides and nitrides of the

\footnotetext{
2 The authors are grateful to the workers of the Laboratory for Structural Methods of Analysis and Properties of Materials and Nanomaterials of the UrFU TsKP M. S. Karabanalov and S. V. Belikov for supplying us with results obtained at the laboratory.
} 


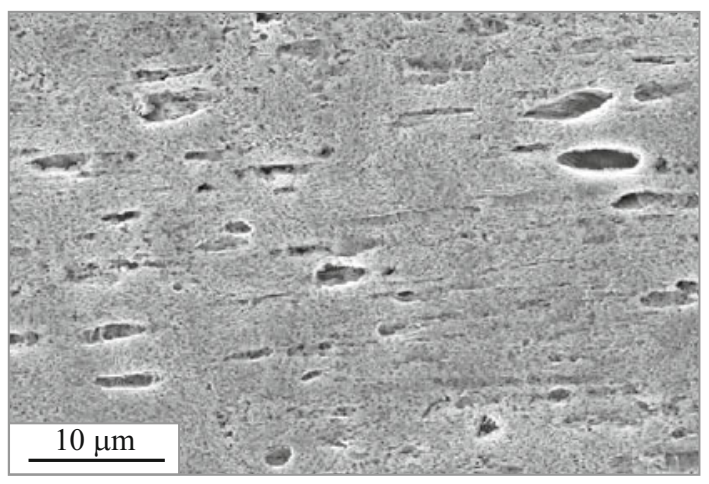

Fig. 1. Initial microstructure of a foil from intermetallic alloy $\mathrm{Ti}-$ $23 \mathrm{Al}-26 \mathrm{Nb}$.

main components; to remove them before sintering the surface was etched in an aqueous solution of nitric and hydrofluoric acids. The structure of the aluminum foils contained iron-silicon aluminides up to $2 \mu \mathrm{m}$ in size.

The foil pack was sintered in an HP D 25 device imported from the FCT Systeme GmbH (Germany) in vacuum of about $10^{-1} \mathrm{~Pa}$. A drawing of the device is presented in Fig. 2. The fixture material was high-strength graphite. The sintering temperature was $500^{\circ} \mathrm{C}$ at a constant pressing pressure of $60 \mathrm{MPa}$. The total treatment time was $15 \mathrm{~min}$. The sintered specimens had no pres. The total shrinkage during sintering attained $3 \%$. Being an advancement of the process of hot pressing plasma-spark sintering is based on the phenomenon of the appearance of a spark discharge between interfaces of a powder or a layered material upon passage of high-power direct current pulses at a relatively low voltage, when a current pulse instantaneously generates spark plasma at a high local temperature (up to $10,000^{\circ} \mathrm{C}$ ). The spark energy evaporates the contaminating substances and oxides on the surfaces of the particles before the formation of a bridge. Then the Joule heat concentrates on the interfaces giving rise to plastic strain responsible for a high density [9].

The specimens obtained were later subjected to vacuum annealing in two stages. The annealing temperature in the first stage was lower than the temperature of melting of aluminum and amounted to $650^{\circ} \mathrm{C}$; the annealing was performed for $0.5,2.5$ and $6 \mathrm{~h}$. Increase in the annealing temperature to $700^{\circ} \mathrm{C}$, i.e., above the temperature of melting of aluminum, was accompanied by formation of pores, which is impermissible. In the second stage we annealed the specimens (annealed in the first stage at $650^{\circ} \mathrm{C}$ for $6 \mathrm{~h}$ ) now at 800 and $1000^{\circ} \mathrm{C}$ (below and above $T_{\mathrm{pt}}$ of alloy $\mathrm{Ti}-23 \% \mathrm{Al}-$ $26 \% \mathrm{Nb}$, respectively). The hold time was 1,5 , and $12 \mathrm{~h}$.

Metallographic studies and analysis of the distribution of the main alloying elements were performed using a "Jeol JSM-6490LV" scanning electron microscope (SEM) equipped with an Oxford Instruments Inca Energy 350 system for microscopic $\mathrm{x}$-ray spectrum analysis at an accelerating voltage of $20 \mathrm{kV}$ in the mode of detection of backscattered electrons for visualizing the material contrast. X-ray diffraction

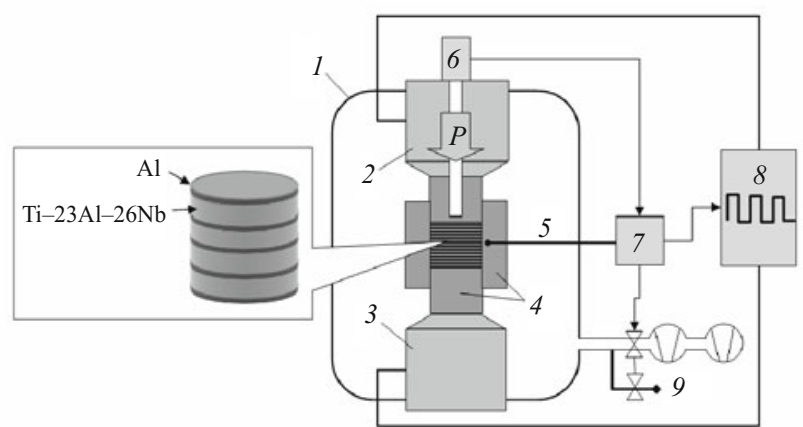

Fig. 2. Drawing of device for plasma-spark sintering: 1 ) vacuum chamber; 2 ) upper (mobile) stem; 3 ) lower stem; 4 ) graphite set; 5 ) thermocouple; 6 ) pyrometer; 7 ) system controller; 8 ) pulse generator of direct current; 9 ) modules for creating furnace atmosphere.

phase analysis was performed with the help of a Bruker D8 Advance x-ray diffractometer in copper $K_{\alpha}$ radiation at a voltage of $40 \mathrm{kV}$ and a tube current of $40 \mathrm{~mA}$.

\section{RESULTS AND DISCUSSION}

Materials to be used for diffusion joining by traditional processes require careful preparation of the contact surfaces. In the present work we used only etching of the intermetallic foils. Figure $3 a$ presents the microstructure of a layered material right after sintering. We should note good contact between aluminum and the intermetallic layers, which means that there is no need for raising the pressing pressure. The low temperature and short duration of the sintering operation are responsible for the absence of well-manifested diffusion zones on the interfaces.

Annealing at $650^{\circ} \mathrm{C}$. The study of the structure of specimens after vacuum annealing showed active redistribution of titanium into aluminum and formation of an $\mathrm{Al}_{3} \mathrm{Ti}$ intermetallic phase. However, after the holds for 0.5 and $2.5 \mathrm{~h}$ the metal contained zones of pure aluminum not involved into diffusion, whereas after a 6-h hold such zones were absent (Fig. $3 b$ ). Computation and analysis of the structure showed that the $\mathrm{Al} \rightarrow \mathrm{Al}_{3} \mathrm{Ti}$ transition finished completely in $2.5 \mathrm{~h}$ at a $9-\mu \mathrm{m}$ thickness of the aluminum layer (according to the data of preliminary tests) and in $6 \mathrm{~h}$ at a $16-\mu \mathrm{m}$ thickness. Diffusion layers corresponding to phases $\gamma, \alpha_{2}$ and $\mathrm{O}$ were not observed.

Annealing at $800^{\circ} \mathrm{C}$. According to the data of the x-ray diffraction phase analysis, the structure of the specimen subjected to vacuum annealing at $800^{\circ} \mathrm{C}$ for $1 \mathrm{~h}$ contained phases $\varepsilon-\mathrm{Al}_{3} \mathrm{Ti}, \eta-\mathrm{Al}_{2} \mathrm{Ti}$ and $\gamma$-AlTi. In addition, the diffractograms exhibited a set of reflections belonging, according to the data of [10], to a $\sigma$-phase. Analyzing the SEM images and the data of the x-ray spectrum analysis we estimated the mean length of the diffusion zone at $20 \mu \mathrm{m}$. In the central layers of the intermetallic foil the phase and structural com- 

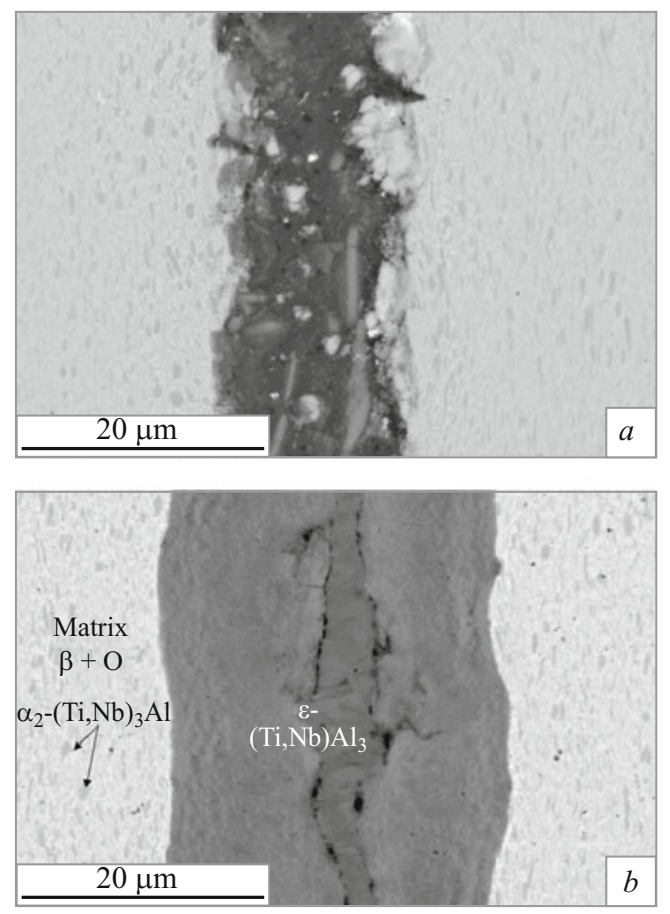

Fig. 3. Microstructure of specimens after sintering $(a)$ and after annealing at $650^{\circ} \mathrm{C}$ for $6 \mathrm{~h}(b)$, SEM.

position was typical for alloy $\mathrm{Ti}-23 \% \mathrm{Al}-26 \% \mathrm{Nb}$ after such heat treatment, i.e., segregations of $\alpha_{2}-(\mathrm{Ti}, \mathrm{Nb})_{3} \mathrm{Al}$ in a matrix represented by a mixture of $\mathrm{O}$ - and $\beta$-phases.

With distance from the center of the intermetallic foil the content of aluminum increased somewhat. In the contrast of backscattered electrons we could observe on the SEM image a multiphase layer (Fig. $4 a$ ) with niobium content of about 20 at.\% (the data of the x-ray spectrum analysis). Such a layer can only be an intermetallic compound of type $\mathrm{Ti}_{2} \mathrm{NbAl}$ (O-phase, point 5 in Fig. $4 b$ ). This confirms the possibility of existence of a monoregion of this phase at a temperature of $800^{\circ} \mathrm{C}$, which agrees with the computational results of the isothermal section of the ternary diagram given in [11]. The layer of the O-phase has a well manifested boundary oriented normally to the diffusion flows of titanium and aluminum atoms.

The next layer is characterized by a virtually invariable content of aluminum; the strong material contrast in the SEM image indicates the presence of two phases with different contents of the heavy alloying element, i.e., niobium. According to the ternary diagram, the composition of the light $34 \mathrm{Ti}-33 \mathrm{Al}-33 \mathrm{Nb}$ phase matches a $\sigma$-phase (TiAlNb) (point 3 in Fig. $4 b$ ). The composition of the dark phase $56 \mathrm{Ti}-30 \mathrm{Al}-14 \mathrm{Nb}$ gets into the domain of existence of an $\alpha_{2}$-phase $\left[(\mathrm{Ti}, \mathrm{Nb})_{2} \mathrm{Al}\right.$, point 4 in Fig. $\left.\left.4 b\right)\right]$. The boundary between these two phases goes almost transversely to the redistribution front. It should be noted that the single-phase layers of the $\alpha_{2}$-phase are located over the external boundaries of these zones on the side of the intermetallic foil and
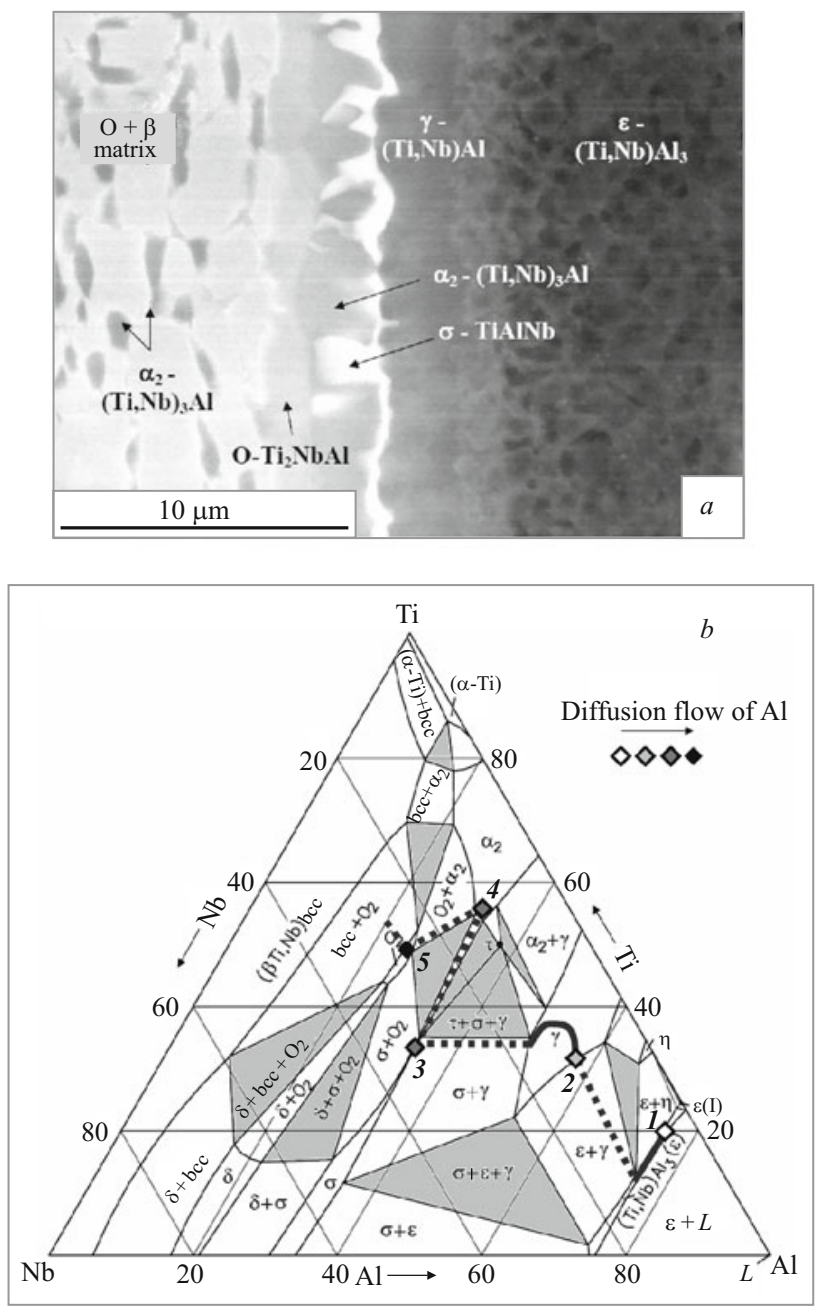

Fig. 4. Microstructure of a sintered specimen after 1-h annealing at $800^{\circ} \mathrm{C}(a)$ and phase composition of the diffusion layer according to the $\mathrm{Ti}-\mathrm{Al}-\mathrm{Nb}$ ternary diagram [11] (b).

the layers of the $\sigma$-phase go on the side of the aluminum foil. The problem is that both of the detected phases do not get into the "intermetallic layer $\leftrightarrow \mathrm{Al}$ " line of redistribution of the chemical composition (Fig. $4 b$ ) but are arranged symmetrically on both sides of the latter. In this case the scheme of phase transformations can be represented as follows.

The layer of the $\sigma$-phase appearing on the side of the aluminum layer is enriched with niobium. The appearance of the next $\alpha_{2}$-layer with reduced content of niobium creates conditions for further growth of the existing $\sigma$-phase. Since the content of aluminum in both phases is virtually the same and given that niobium is redistributed over a common front of growth normally to the diffusion flows of $\mathrm{Ti}$ and $\mathrm{Al}$, the two phases can grow simultaneously. This is conformed by the predominantly normal arrangement of the $\alpha_{2} / \sigma$ boundaries with respect to the other diffusion layers. The phases denoted by letter $\tau$ in the ternary diagram (Fig. $4 b$ ) have not been detected. 


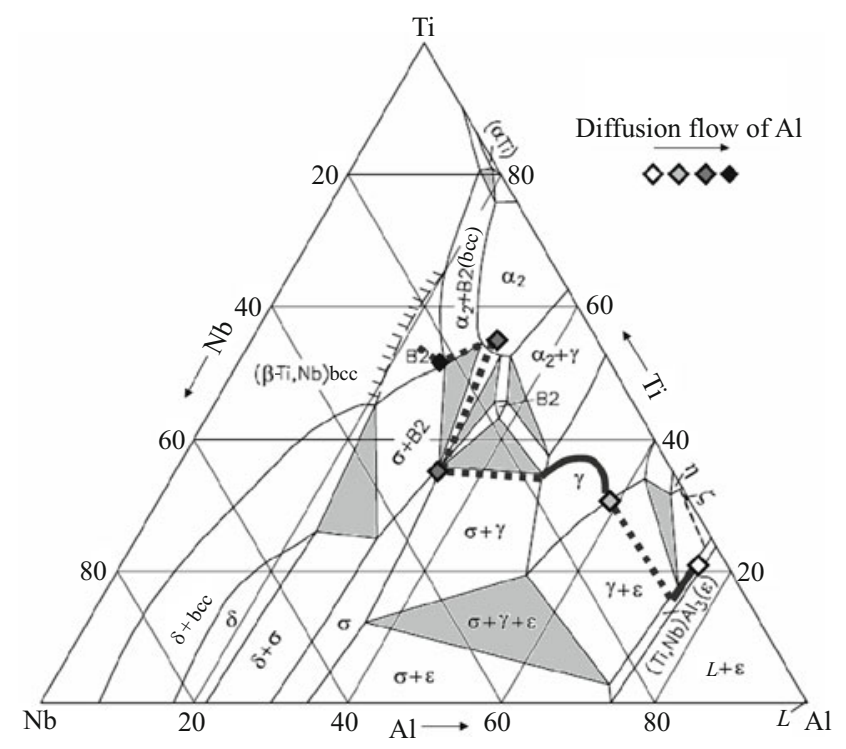

Fig. 5. Phase composition of the diffusion layer of specimens annealed at $1000^{\circ} \mathrm{C}$ for $1 \mathrm{~h}$ in accordance with the ternary $\mathrm{Ti}-\mathrm{Al}-\mathrm{Nb}$ diagram [11].

The next phase along the direction to the former $\mathrm{Al}$ layer is a $\gamma$-phase with a thickness of about $2 \mu \mathrm{m}$.

The layer retained in the place of the former $\mathrm{Al}$ foil is not a single-phase one; its chemical composition corresponds primarily to an $\varepsilon-(\mathrm{Ti}, \mathrm{Nb}) \mathrm{Al}_{3}$ phase (point 1 in Fig. $4 b$ ). However, in some regions the content of $\mathrm{Nb}$ exceeds that possible for the $\sigma$-phase and matches the stoichiometry of $\mathrm{Al}_{2}(\mathrm{Ti}, \mathrm{Nb})$, which agrees with the data of the $\mathrm{x}$-ray diffraction phase analysis. These phases may form as a result of decomposition of a high-temperature $\mathrm{Al}_{5} \mathrm{Ti}_{2}$ phase during cooling; the reasoning is given in [12]. In other respects the specimen exhibits good correspondence between the experimental and the computed data (the points with chemical composition determined by the MXRSA are deposited on the computed diagram of Fig. $4 b$; the experimental data are presented in Table 1).

Annealing at $1000^{\circ} \mathrm{C}$ for $1 \mathrm{~h}$. The structure of the diffusion zone of the specimen annealed at $1000^{\circ} \mathrm{C}$ is similar on the whole to that of the specimen annealed at $800^{\circ} \mathrm{C}$ except for the absent layer of an O-phase. It should be stressed that the diffusion is implemented through formation of a $\sigma$-phase and not of a $\beta^{\prime}(\mathrm{B} 2)$-phase as it could be expected from analysis of the phase diagram (Fig. 5).

Annealing at $1000^{\circ} \mathrm{C}$ for $12 \mathrm{~h}$. The results of the XRDPA reflect the presence of $\mathrm{O}-, \beta-, \beta^{\prime}-, \alpha_{2}$ and $\gamma$-phases in the structure of this specimen. Just like in the specimen annealed at $800^{\circ} \mathrm{C}$ the diffraction spectra contain a set of lines ascribed to a $\sigma$-phase. The length of the diffusion zone in this case (Fig. $6 a$ ) is $50 \mu \mathrm{m}$. The average chemical composition of the diffusion zone according to the data of the MXRSA is $30 \mathrm{Al}-$ $50 \mathrm{Ti}-20 \mathrm{Nb}$; in the equilibrium state this should correspond
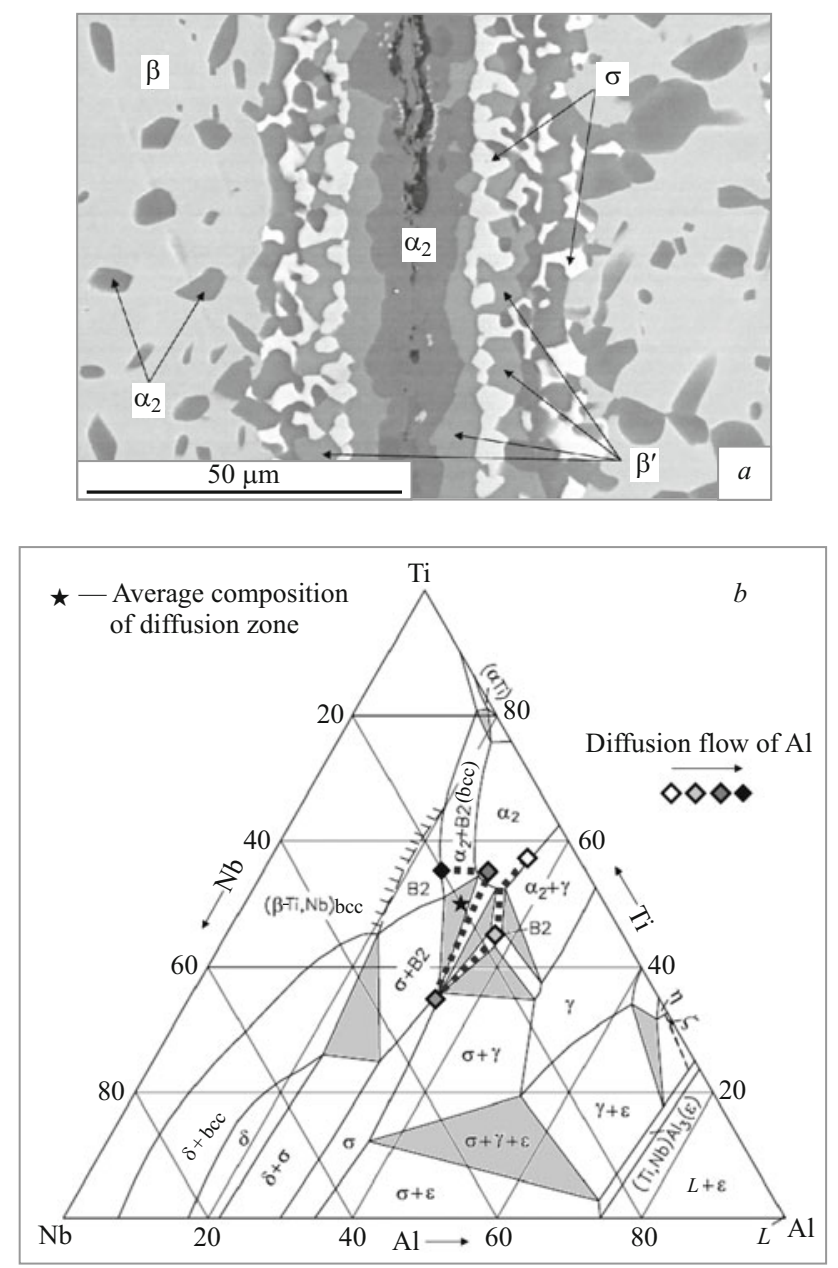

Fig. 6. Microstructure of a sintered specimen after 12-h annealing at $1000^{\circ} \mathrm{C}(a)$ and phase composition of the diffusion layer according to the $\mathrm{Ti}-\mathrm{Al}-\mathrm{Nb}$ ternary diagram $[11](b)$.

to a mixture of B2- and $\alpha_{2}$-phases with a low content of $\sigma$-phase (Fig. $6 b$ ).

The composition of the central regions of the former intermetallic foil contains an elevated content of aluminum [25-26 at.\%]. This fact shows that the flow of aluminum has reached the center of the foil, and its content is on the line of the limiting solubility in $\beta$-phase at 23 at.\% of niobium. The general phase composition is a mixture of four

TABLE 1. MXRSA Data for a Specimen Annealed at $850^{\circ} \mathrm{C}$

\begin{tabular}{|c|c|c|c|c|}
\hline \multirow{2}{*}{$\begin{array}{l}\text { No. of point } \\
\text { in the diagram } \\
\text { of Fig. } 4 b\end{array}$} & \multicolumn{3}{|c|}{ Content of element, at.\% } & \multirow{2}{*}{ Phase } \\
\hline & $\mathrm{Al}$ & $\mathrm{Ti}$ & $\mathrm{Nb}$ & \\
\hline 1 & $66-73$ & $15-19$ & $6-9$ & $\varepsilon-(\mathrm{Ti}, \mathrm{Nb}) \mathrm{Al}_{3}$ \\
\hline 2 & $50-58$ & $32-38$ & $12-17$ & $\gamma-(\mathrm{Ti}, \mathrm{Nb}) \mathrm{Al}$ \\
\hline 3 & 33 & 34 & 33 & $\sigma-\mathrm{TiNbAl}$ \\
\hline 4 & 30 & 56 & 14 & $\alpha_{2}-(\mathrm{Ti}, \mathrm{Nb})_{3} \mathrm{Al}$ \\
\hline 5 & 24 & 53 & 23 & $\mathrm{O}-\mathrm{Ti}_{2} \mathrm{AlNb}$ \\
\hline
\end{tabular}




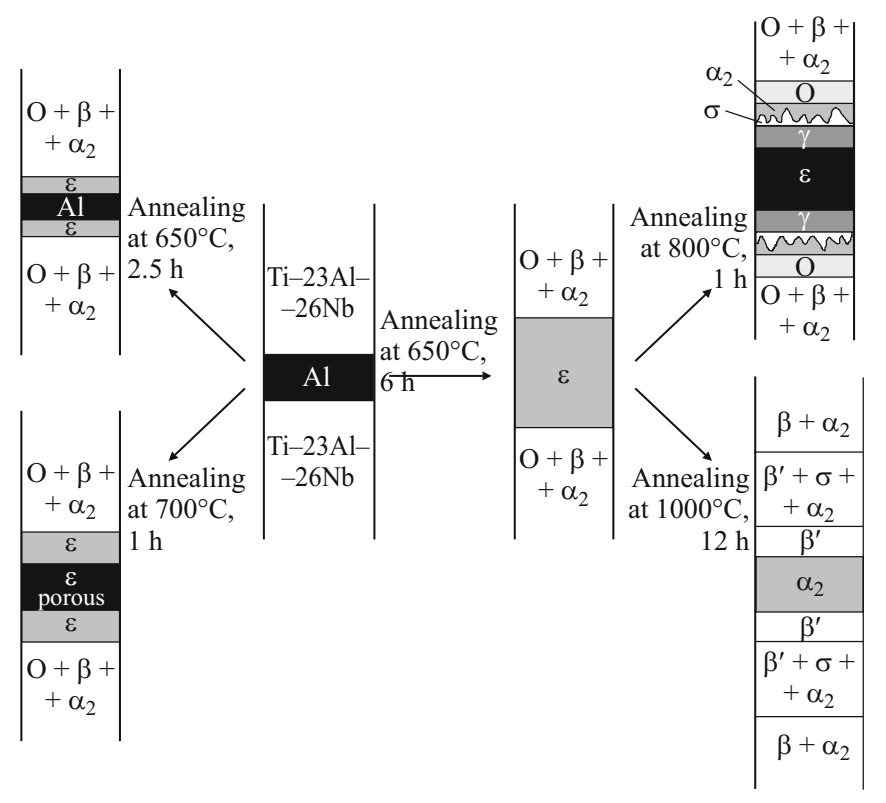

Fig. 7. Schematic representation of the phase composition and structure of diffusion layers of a "titanium alloy - aluminum" layered composite (in high-temperature state) after different modes of treatment.

phases, i.e., the three equilibrium phases are accompanied by a $\beta^{\prime}$-phase.

For the specimen annealed at $1000^{\circ} \mathrm{C}$ for $12 \mathrm{~h}$ we observed an interesting fact. In the zone of the former aluminum layer the content of aluminum was lower than in the subsequent diffusion layers. The phase composition of this region was represented by an $\alpha_{2}$-phase (Fig. $6 a$ ). Its appearance will be explainable if we assume that in the case in question the phase composition is already controlled not so much by the redistribution of aluminum as by the diffusion flow of niobium from the regions of the former intermetallic foil. Since the diffusion mobility of the $\mathrm{Al}$ atoms is higher than that of $\mathrm{Nb}$, the concentration gradient of the latter should be decisive for the structure of the layers. Lowering of the content of niobium predetermines the possibility of existence of only $\alpha_{2}$-phase. As a result, the phase composition in the central regions of the former aluminum layers changes as follows: $\varepsilon-(\mathrm{Ti}, \mathrm{Nb}) \mathrm{Al}_{3} \rightarrow \gamma-(\mathrm{Ti}, \mathrm{Nb}) \mathrm{Al} \rightarrow \alpha_{2}-(\mathrm{Ti}, \mathrm{Nb})_{3} \mathrm{Al}$.

The central layer of the $\alpha_{2}$-phase is surrounded by layers of phase $\beta^{\prime}(\mathrm{B} 2)$, the appearance of which also seems to be controlled by the content of niobium. When the growth front displaces forward, intermediate phases $\gamma, \sigma$, and $\alpha_{2}$ appear successively. When the front moves backward, a $\beta^{\prime}$ (B2)-phase forms on the $\alpha_{2} / \sigma$ and $\gamma / \sigma$ boundaries though it is absent in the forward motion. With allowance for the chemical composition, the $\beta^{\prime}(\mathrm{B} 2)$-phase is an intermediate one and should dissolve progressively due to formation of the $\alpha_{2}$ - and $\sigma$-phases. Then goes the earlier formed mixture of the $\sigma$ - and $\alpha_{2}$-phases. The central layers of the former intermetallic foil are chiefly occupied by a high-temperature $\beta$-phase which contains coarse segregations of phase $\alpha_{2}$. Such segregations seem to have form due to inconsiderable temperature fluctuations during the hold or during cooling. A model of the development of processes in the course of redistribution of the elements is presented in Fig. $6 b$.

It is obvious that in all the cases considered the process of redistribution of the chemical elements is incomplete. The phase composition of the specimen annealed at $1000^{\circ} \mathrm{C}$ for $12 \mathrm{~h}$ is the closest to the equilibrium situation.

The experimental data obtained are generalized in Fig. 7 in the form of a scheme of variation of the phase composition of the studied material after different variants of heat treatment. We expect that to make the redistribution more effective the homogenizing annealing should be performed at a temperature of about $1200^{\circ} \mathrm{C}$, which provides closure of regions $\gamma, \beta^{\prime}(\mathrm{B} 2)$ and $\beta$ in the phase diagram and makes the diffusion path $\gamma \rightarrow \beta^{\prime}(\mathrm{B} 2)$ possible.

\section{CONCLUSIONS}

1. The possibility of application of plasma-spark sintering for making layered composites from chemically active materials with an easily oxidizing surface ( $\mathrm{Ti}, \mathrm{Nb}, \mathrm{Al})$ has been shown.

2. Annealing of "titanium alloy - aluminum" composites at a temperature exceeding that of melting of $\mathrm{Al}$ is accompanied by formation of pores and is inadmissible prior to the end of the $\mathrm{Al} \rightarrow \mathrm{Al}_{3} \mathrm{Ti}$ transformation. Accordingly, the sintering process should be performed in two stages, namely, the first annealing at $650^{\circ} \mathrm{C}$ for $2.5-6 \mathrm{~h}$ depending on the thickness of the initial aluminum foil until full completion of the $\mathrm{Al} \rightarrow \mathrm{Al}_{3}$ Ti transition and the second annealing at a high temperature to obtain the required phase composition.

3. On the whole the agreement between the computed and experimental $\mathrm{Ti}-\mathrm{Nb}-\mathrm{Al}$ diagrams is shown to be good. However, the appearance of a phase with composition close to the stoichiometric $\mathrm{Al}_{2}(\mathrm{Ti}, \mathrm{Nb})$ with $\mathrm{Nb}$ content exceeding the possible one in the $\mathrm{Al}$ corner of the diagram may be an indication of a wider range of homogeneity of the $\varepsilon$-phase.

4. In the initial stages the diffusion transformations in layered materials of the $\mathrm{Ti}-\mathrm{Al}-\mathrm{Nb}$ system are controlled by the diffusion of aluminum; in the final stages they are controlled by the diffusion of niobium.

5. Formation of intermediate phases hinders the processes of redistribution of elements (primarily of $\mathrm{Nb}$ ). The forward displacement of the crystallization front is accompanied by successive formation of intermediate phases $\gamma, \sigma$ and $\alpha_{2}$. In backward motion of the front a $\beta^{\prime}(\mathrm{B} 2)$ phase, which is absent in the forward motion, forms on the $\alpha_{2} / \sigma$ and $\gamma / \sigma$ boundaries. The front of the $\sigma / \alpha_{2}$ separation is directed over the main front, which is a consequence of the mutually perpendicular redistribution of $\mathrm{Al}$ and $\mathrm{Nb}$ atoms. 
The work has been performed with support of the grant of the Ural Federal University for scientific research of young candidates of science within State Contract No. 02.740.11.0160 of the Federal Target Program "Scientific and Scientific-Pedagogical Manpower of Innovative Russia."

\section{REFERENCES}

1. V. N. Moiseev, "Titanium in Russia," Metalloved. Term. Obrab. Met., No. 8, 23 - 29 (2005).

2. B. A. Kolachev, V. A. Livanov, and V. I. Elagin, Metal Science and Heat Treatment of Nonferrous Metals and Alloys [in Russian], MISiS, Moscow (1999), 412 p.

3. J. Dutkiewicz, W. Maziarz, H. Heinrich, and G. Kostorz, "Structure of $\mathrm{Ti}-\mathrm{Al}-\mathrm{Nb}$ intermetallics produced by mechanical alloying and hot-pressing techniques," Mater. Chem. Phys., 81(2-3), $414-416$ (2003).

4. O. Shuleshova, T. G. Woodcock, H.-G. Lindenkreuz, et al., "Metastable phase formation in $\mathrm{Ti}-\mathrm{Al}-\mathrm{Nb}$ undercooled melts," Acta Mater., 55, 2, 681 - 689 (2007).

5. D. Banerjee, A. K. Gogia, T. K. Nandy, and V. A. Joshi, "A new ordered orthorhombic phase in a $\mathrm{Ti}_{3} \mathrm{Al}-\mathrm{Nb}$ alloy," Acta Metallurg., 36(4), 871 - 882 (1988).
6. K. Muralledharan and D. Banerjee, "Deformation of $\mathrm{O}$ and $\alpha_{2}$-phase in the $\mathrm{Ti}-\mathrm{Al}-\mathrm{Nb}$ system," Philos. Mag. A, 71(5), $1011-1036$ (1995)

7. S. L. Demakov, A. A. Popov, E. M. Komolikova, and F. V. Vodolazskiy, "A diagram of isothermal decomposition of the $\beta$-phase in $\mathrm{Ti}-22 \mathrm{Al}-26 \mathrm{Nb}-0.5 \mathrm{Zr}-0.4 \mathrm{Mo}$ alloy," Mater Sci., 44(3), 374 - 379 (2008).

8. A. Helwig, M. Palm, and G. Inden, "Phase equilibria in the $\mathrm{Al}-\mathrm{Nb}-\mathrm{Ti}$ system at high temperatures," Intermetallics, $6(2)$, 79 - 94 (1998).

9. J. Räthel, M. Herrmann, and W. Beckert, "Temperature distribution for electrically conductive and non-conductive materials during field assisted sintering (FAST)," J. Europ. Ceram. Soc., 29(8), 1419 - 1425 (2009).

10. J. K. Leonard, J. C. Mishurda, and V. K. Vasudevan, "Phase equilibria at $1100^{\circ} \mathrm{C}$ in the $\mathrm{Nb}-\mathrm{Ti}-\mathrm{Al}$ system," Mater. Sci. Eng. A, 329-331, $282-288$ (2002).

11. V. Raghavan, "Al - $\mathrm{Nb}-\mathrm{Ti}$ (aluminum - niobium - titanium)," J. Phase Equil. Diffus., 31(1), 47 - 52 (2010).

12. M. Palm, L. C. Zhang, F. Stein, and G. Sauthoff, "Phases and phase equilibria in the Al-rich part of the $\mathrm{Al}$ - Ti system above $900^{\circ} \mathrm{C}$," Intermetallics, 10(6), 523 - 540 (2002). 